\title{
La España de los historiadores rusos (Segunda mitad del siglo XIX - comienzos del siglo $\mathrm{XX}$ )
}

\author{
Vladimir VEDYUSHKIN \\ Academia de Ciencias de Rusia \\ vedyushkin@mail.ru
}

Recibido: Mayo de 2013

Aceptado: Diciembre de 2013

\begin{abstract}
Resumen
Este artículo tiene un doble objetivo. Por una parte analizar el origen de los estudios sobre la historia de España en la ciencia histórica rusa de la segunda mitad del siglo XIX y comienzos del siglo XX y mostrar la estrecha relación entre los temas preferidos por los hispanistas y la realidad rusa de aquel tiempo. Por otro lado examinar los rasgos característicos de la imagen de España en la obra del historiador hispanista Vladímir Piskorski (1867-1910). Se analizan las memorias de Piskorski y su informe oficial sobre sus actividades científicas en España que contienen datos importantes sobre la ciencia histórica española de aquel tiempo.
\end{abstract}

Palabras clave: historiografía, Piskorski, imagen de España, memorias, informe oficial

Spain of Russian historians (the second half of the 19th century and the beginning of the 20th century)

\begin{abstract}
This article has a double aim. On the one hand it analyses the origins of the studies about medieval Spain in Russian historical science in the second half of the 19th century and at the beginning of the 20th century and to show the connection between the themes of researches and Russian realities of this time. On the other hand it deals with some characteristic features of the image of Spain in the works written by historian Vladimir Piskorski (1867-1910). Memoirs of Piskorski and his official report about his scholarly mission in Spain are examined; both contain important data about Spanish historical science of this time.
\end{abstract}

Key words: historiography, Piskorski, image of Spain, memoirs, official report

En las imágenes de cada país, nacidas de la pluma de uno u otro autor, junto con los estereotipos que se transmiten de uno a otro autor y de una a otra época, siempre son interesantes las diferencias visibles. Por un lado, están las imágenes de los cambios, cuando la España de una época se describe de manera distinta que la España de otra época. Por otro lado, las imágenes de España existentes en los relatos de los viajeros de un mismo tiempo también pueden diferenciarse mucho una de la otra. El diplomático percibe el país ajeno de manera distinta que el mercader; el militar de otra manera que el hombre de arte, la persona bien educada de otra manera que la inculta. 
Las descripciones de los viajeros rusos de mediados y de la segunda mitad del siglo XIX -quizás el periodo clásico para este género- nos muestran el muy rico espectro de las percepciones socioprofesionales sobre España: la del compositor Mijaíl Glinka, el eclesiástico Konstantín Kustódiev, el geógrafo y sociólogo Lev Méchnikov, el pintor Konstantín Korovin, el periodista y escritor Vasili NemiróvichDánchenko y muchos otros.

Hasta los años noventa faltaba en este abanico la mirada del historiador-hispanista. Hasta aquel momento no había habido en Rusia historiadores que se especializasen en la historia de España. Pero el historiador que normalmente se considera como el fundador de los estudios en Rusia sobre la Edad Media europea, Timoféi Granovski, escribió un ensayo sobre la Edad Media española (ГРАНОВСКИЙ 1866: 166-189). Se trata de un análisis crítico de la investigación de Dozy, hispanista holandés de origen francés, dedicada a la comparación del Cid -personaje de la historia española del siglo XI- con el Cid del Cantar de mio Cid y de los romances.

Apenas 20 años después de la muerte de Granovski, la escuela rusa de historiadores alcanzó su época de florecimiento en las obras de historiadores como Pável Vinográdov, Iván Luchitski, Maksím Kovalevski, Nikolái Karéiev. Ninguno de ellos fue primordialmente hispanista, pero el interés por la historia de España alcanzó con sus estudios carácter científico. La historia de España llamaba su atención gracias a la posibilidad de poner al descubierto las leyes del desarrollo comunes de la historia europea en un ejemplo casi desconocido y exótico. Entre estas leyes del desarrollo, el mayor interés lo provocaban las más relacionadas con el desarrollo de Rusia y los problemas más urgentes de la vida rusa. Los historiadores rusos de esta generación, así como más tarde sus discípulos, se interesaban por temas tales como la historia económica y la historia del campesinado y su lucha por la libertad y por la tierra.

Así, Maksím Kovalevski, famoso historiador y sociólogo, incluía numerosos datos de la historia de España en una de sus obras más conocidas, El crecimiento económico de Europa antes del surgimiento de la economía capitalista (КОВАЛЕВСКИЙ 1898-1903). Fue también autor de un artículo dedicado especialmente a un episodio muy interesante de la historia española: "El pueblo en el drama de Lope de Vega Fuenteovejuna" (КОВАЛЕВСКИЙ 1891: 97-130).. El historiador, testigo de los grandes y violentos cambios en el mundo rural ruso, tiene un lógico interés en el tema de la protesta y levantamiento de los campesinos y en su reflejo en la rebelión campesina en Fuenteovejuna, sin importarle que ésta fuese más la excepción que la regla en el reinado de los Reyes Católicos.

Iván Luchitski, profesor de la Universidad de Kiev, fue quizás el primer historiador ruso en consultar de manera sistemática los archivos españoles. El interés de Luchitski en la historia de España, como el de Kovalevski, se origina en su pensamiento político. El científico buscaba en la historia de los países europeos las respuestas a las preguntas que la realidad histórica planteaba a la sociedad rusa. El problema más importante del desarrollo de Rusia en los decenios tras la abolición de la servidumbre en 1861 es el campesino.

Como se sabe, Luchitski fue partidario convencido de la teoría de la comunidad y suponía que la comunidad campesina es un fenómeno universal y una fase necesaria en el desarrollo de cada pueblo; por eso quería comprobar esta tesis con ejem- 
plos de varios países, entre ellos España. Estudiando el tema en los archivos españoles, Luchitski encontró muchos datos sobre la existencia de las behetrías, las antiguas organizaciones de campesinos libres que tenían el derecho de elegir a su señor. El historiador llegó a la conclusión de que las behetrías fueron una variante específicamente española de comunidad (ЛУЧИЦКИЙ 1882, 1883).

En el artículo denominado "La comunidad de la tierra en los Pirineos" (ЛУЧИЦКИЙ 1883) Luchitski, apoyando sus tesis con numerosos documentos sacados de los archivos, quería mostrar la existencia de formas comunales de propiedad de la tierra, sobre todo en el ejemplo de las behetrías. Quedó convencido de haber probado la existencia de la propiedad comunal de la tierra en la Península Ibérica durante toda la Edad Media y hasta nuestros días. Él quería mostrar el denominador común a toda la riqueza de la realidad histórica de la aldea española. Luchitski subrayaba los rasgos comunes entre la behetría y la comunidad rusa ignorando todas sus peculiaridades individuales.

Estos resultados de las investigaciones de Luchitski no fueron sin embargo aceptados por su discípulo favorito y amigo, Vladímir Piskorski, el hispanista ruso y ucraniano más conocido, cuya figura merece una atención especial. No se puede decir que esté olvidado en Rusia y en Ucrania ${ }^{1}$, pero de hecho su obra continúa hasta ahora estudiada sólo muy superficialmente. En los años ochenta Emilio Sáez, conocido historiador español y gran partidario del desarrollo de las relaciones científicas entre los historiadores de España y la, en aquel tiempo, URSS, quería estudiar en detalle las estancias de Piskorski en España, pero su prematura muerte impidió realizar estas planes, y desde entonces casi nadie ha estudiado esta parte de la actividad científica de Piskorski. Además de la publicación de las memorias de Piskorski sobre sus estancias en Еspaña (ПИСКОРСКИЙ 1992: 178-191), solamente se puede mencionar algunas páginas de un artículo de Irina Pichúguina y Lidia Mílskaia (МИЛЬСКАЯ 1975: 230-249) y el artículo de Elena Nóvikova-Piskórskaia dedicado a las relaciones amistosas entre Vladímir Piskorski y Víctor Balaguer (НОВИКОВА-ПИСКОРСКАЯ 2010: 307-311).

Piskorski nació en Odessa en 1867. En 1890 se graduó en la Facultad de Historia y Filología de la Universidad de San Vladimiro de Kiev. Murió en 1910 a los 43 años. Durante los 20 años de su actividad científica y pedagógica Piskorski impartió mucha enseñanza y publicó cinco libros (sin contar los manuales de sus cursos). Fue él quien escribió la mayoría de los artículos sobre la historia de la Edad Media y Moderna para la enciclopedia rusa más conocida de aquel tiempo, Diccionario Enciclopédico Brockhaus y Efron. Gracias a esta su actividad, sus ideas sobre la historia de España fueron bien conocidas para círculos de lectores más amplios.

El primero de sus libros, un estudio monográfico sobre un florentino del siglo XVI, Francesco Ferrucci, fue en realidad la edición de su memoria de licenciatura (ПИСКОРСКИЙ 1891). Рoco después de su publicación, Piskorski empezó sus estudios sobre la España medieval.

\footnotetext{
1 Ver al respecto, entre otros, los trabajos de Lidia Mílskaia, Irina Pichúguina, Elena Nóvikova-Piskórskaia, Svetlana Luchítskaia: МИЛЬСКАЯ (1975: 230-249); МИЛЬСКАЯ (2000: 125-133); НОВИКОВА-ПИСКОРСКАЯ (2010: 307-311); НОВІКОВА (2011: 7-13); ЛУЧИЦКАЯ (2011: 45-53).
} 
Desde el inicio se interesó en dos temas, a primera vista poco relacionados uno con otro: la historia de la representación estamental en Castilla y la historia del desarrollo y de la abolición de la servidumbre de los campesinos en Cataluña. En realidad, esta combinación de intereses es fácil de explicar: cada uno de ellos es una proyección en la España medieval de un problema importante de la vida rusa de finales del siglo XIX; por un lado, la suerte del campesinado recién liberado de la servidumbre; por otro lado, la monarquía absoluta en un tiempo en que la necesidad de limitarla e introducir el Estado constitucional se sentía más y más.

En los años 1896 y 1897 Piskorski viajó a Europa Occidental para preparar su libro sobre las cortes castellanas. Para empezar, Piskorski, gracias a las cartas de presentación recibidas de su maestro Luchitski, bien conocido en Francia, se familiarizó con la vida científica de París, con sus bibliotecas y archivos, con el sistema de enseñanza en las universidades francesas. Conoció a los historiadores hispanistas franceses, incluyendo al más conocido entre ellos, Alfredo Morel Fatio, quienes le dieron cartas de recomendación para los historiadores y archiveros españoles (ПИСКОРСКИЙ (1992: 183). Llegó a Madrid en marzo de 1896.

Durante medio año trabajó en todos los archivos y bibliotecas principales de Madrid en las que había posibilidad de encontrar algo interesante para sus temas; viajó para consultar los archivos y bibliotecas de Toledo, El Escorial, Valladolid, Simancas y Murcia. Durante esta estancia prestó atención principalmente al tema de las cortes de Castilla, pero al mismo tiempo recopilaba todo que encontraba adecuado para su otro tema, el de la servidumbre en Cataluña. Regresando durante el invierno a París, el año siguiente viene de nuevo a España, esta vez a Cataluña, para centrarse exclusivamente en su segundo tema. De tal modo, reunió durante estos dos años los datos para dos libros. Más aún, el primer libro fue escrito, preparado para la edición y publicado a finales del año 1897 (ПИСКОРСКИЙ 1897), dentro de los mismos dos años.

El otro libro, La servidumbre en Cataluña en la Edad Media, salió a la luz en 1901 (ПИСКОРСКИЙ 1901). Un año más tarde, Piskorski publica la primera (y hasta ahora única) Historia de España y Portugal escrita por un historiador ruso (ПИСКОРСКИЙ 1902).

Al venir a España, Piskorski, joven pero con talento, bien educado y preparado para la búsqueda archivística, atrajo la atención de sus colegas españoles. Tenía cartas de presentación a algunos de ellos por parte de Luchitski o de Morel Fatio. Bastará ahora enumerar algunos de los políticos, diplomáticos, científicos y escritores con los cuales fue bien conocido: Víctor Balaguer, Francisco Pi y Margall, Marcelino Menéndez Pelayo, Antonio Paz y Meliá, Joaquín Costa, Rafael Altamira, Nicolás Salmerón, Gaspar Núñez de Arce, marqués de Villalobar y muchos otros (ПИСКОРСКИЙ 1992: 182-183).

Los historiadores españoles apreciaron en lo que valían las obras de Piskorski. Entre sus libros, dos fueron traducidos y editados en España en 1929 y 1930, y uno de ellos, Las cortes de Castilla en el período de tránsito de la Edad Media a la Moderna (1188-1520), fue reeditado en 1977, en un período muy distinto del desarrollo del pensamiento histórico, en calidad de obra clásica que conserva su actualidad. Es muy lógico que en 1901, antes de la publicación de su obra principal para 
la historia de Cataluña, fuese el primer extranjero elegido miembro correspondiente de la Academia Real de Artes en Barcelona (МИЛЬСКАЯ 1975: 249).

Después de estudiar, durante 13 años de su corta vida científica, la historia de España, Piskorski regresó, en los últimos años de su vida, a la historia de Italia, preparando un libro sobre el levantamiento de los Ciompi en Florencia en el siglo XIV. Pero conservaba su interés por la historia de España y acarició planes de reeditar su Historia de España, ampliando y prolongándola hasta el siglo XIX.

Pero regresamos a la estancia de Piskorski en España y, sobre todo, en Madrid. Esta parte de su viaje es más conocida que su estancia en Cataluña. Sus meses en Madrid quedaron reflejados en las cartas de Piskorski a su mujer, más tarde reelaboradas por él mismo en sus memorias (ПИСКОРСКИЙ 1992). Además, un año después de su regreso a Rusia publica un informe oficial sobre su estancia en España (ПИСКОРСКИЙ 1898). Entre otras cosas, cuenta sobre su actividad científica en España e incluye los resúmenes de sus dos libros preparados en España. Pero el contenido del informe sobrepasa los límites de la descripción de su propia actividad científica, y el interés principal de este documento es la descripción que hace del estado de la historiografía española de su tiempo, de las publicaciones principales de los documentos, y del estado de los archivos y de las bibliotecas. Me parece que muchas de sus observaciones no han perdido su actualidad hasta nuestros días y constituyen, en su conjunto, una precisa imagen del mundo científico español, que forma parte importante, aunque poco conocida, de la imagen de España en general. Como en otros relatos de viajeros sobre España, encontramos en las descripciones de Piskorski no pocas paradojas. Dice que la literatura histórica española es muy rica y variada, pero que España continúa siendo el país menos estudiado de toda Europa Occidental. En España hay muchos historiadores que conocen muy bien los logros de la ciencia histórica europea y comprenden la gran importancia de la investigación de la vida social y política del país, pero su actividad raramente tiene resultados positivos. ¿Por qué? Porque los historiadores españoles prefieren estudiar los problemas generales en perjuicio de los problemas particulares, olvidando que la investigación profunda de los primeros es imposible sin los estudios previos de los segundos. Como resultado de esto se dan muchas obras de carácter general y muy escasas monografías. La investigación científica de la historia de España progresa muy poco. Las razones son varias: la deficiencia de la formación universitaria, el mal conocimiento de los idiomas extranjeros, los defectos en la edición de las fuentes primarias para la historia española y, por fin, la falta de independencia científica entre los historiadores españoles, que no siempre se sujetan a las exigencias de la crítica histórica y se dejan arrastrar por la política (ПИСКОРСКИЙ 1898: 28-29).

Por otro lado, los historiadores españoles tienen poca inclinación a tener en cuenta los éxitos de sus predecesores. Como resultado, para cada problema tenemos gran variedad de opiniones inconexas, lo cual dificulta el desarrollo incremental de la historiografía española. Por eso es imposible obtener un punto de vista consensuado para los problemas más importantes de la historia española. Y las obras más importantes sobre la historia de España pertenecen a las plumas de investigadores extranjeros (ПИСКОРСКИЙ 1898: 29). 
Al terminar esta breve, pero muy interesante semblanza del estado de la historiografía española, Piskorski caracteriza una docena de las publicaciones más importantes de documentos para la historia de España. Subrayando las grandes dificultades de carácter objetivo que enfrentan sus editores, Piskorski busca -y encuentraen la historia de su formación los mismos defectos de la historiografía española: la carencia de trabajo sistemático durante la preparación de las colecciones de documentos, el deficiente criterio de sus composiciones, la prisa, los defectos en la crítica de las fuentes. No le gusta la falta de índices o su carácter demasiado lacónico. Se sorprendió al conocer que los índices para una de publicaciones de fuentes más importantes, La España Sagrada de Enrique Flórez, fueron publicados mucho más tarde y, por alguna razón desconocida, en uno de los volúmenes de la "Colección de los documentos inéditos para la historia de España" (ПИСКОРСКИЙ 1898: 33).

Por otro lado, le gusta a Piskorski la actividad de la Real Academia de la Historia en el campo de las publicaciones de los documentos, aunque subraya que la falta de fondos impide a esta Academia realizar más proyectos.

En la parte final de su informe Piskorski caracteriza los archivos y las bibliotecas más grandes de España. Subraya sus riquezas enormes... y la falta o el mal estado de los catálogos. Por eso muchas riquezas manuscritas son un capital muerto, y el éxito del trabajo depende mucho de la figura del director, que conoce bien o mal el contenido de su archivo.

Es muy curioso que Piskorski subraye las dificultades del acceso a los archivos de iglesia; varias veces he oído las mismas lamentaciones por parte de algunos historiadores de nuestros tiempos. Piskorski describe su visita a la biblioteca de la catedral de Toledo; aunque tenía las cartas de presentación por parte de la Nunciatura Apostólica y del padre Fidel Fita, jesuita y famoso historiador, el bibliotecario, mostrando los armarios con antiguos manuscritos, explicó: "Solo se puede ver los manuscritos, pero no se puede leerlos ni copiarlos" (ПИСКОРСКИЙ 1898: 46).

Las memorias de Piskorski casi no tienen temas comunes con su informe y por eso completan muy bien la historia de su estancia en España. Como Botkin 50 años antes (БОТКИН 1976), Piskorski ha llegado a Madrid por Irún, pero viajaba por tren; el viaje entre París y Madrid duró dos días, pero la brevedad del viaje no impide a Piskorski describir a esta parte de su viaje, resaltando (como casi siempre en la literatura de viajes) el contraste entre la naturaleza de Francia y la del norte de España. Tras subrayar las grandes dimensiones de los Pirineos y el crecimiento económico del País Vasco, caracteriza la parte siguiente del camino como "un desierto gris de piedras". En la descripción de Madrid se mezclan estereotipos típicos de los viajeros sobre Madrid (como la crítica del río Manzanares, el cual, según Piskorski, es mucho peor que el rio Lybed en Kiev, afluente del Dniéper'[ПИСКОРСКИЙ 1992: 180]) y una visión muy propia de la realidad madrileña. Dominando muy bien el español y alojándose en el mismo centro de Madrid, Piskorski tuvo muy buenas oportunidades de familiarizarse con la vida de la capital española gracias a sus vecinos en la casa de huéspedes donde vivió.

En sus memorias escribe sobre sus contactos con los historiadores y políticos españoles ya mencionados. Describe en detalle sus entrevistas con el filósofo polaco Lutosławski, quien vivía a la sazón en Madrid, y con su mujer Sofía Casanova 
(ПИСКОРСКИЙ 1992: 183-184); visitaba su salón con regularidad. Conoció bien a la poeta y pintora Blanca de los Ríos. Parece que conoció casi toda la flor de la vida intelectual y artística de Madrid de su tiempo. Sofía Casanova le proponía presentarle en la Corte, pero Piskorski, siendo demócrata convencido, declinó este honor (ПИСКОРСКИЙ 1992: 183).

Otra vez describe, con un grano de ironía, la visita de Mijaíl Rostóvtsev, en aquel tiempo joven y poco conocido pero en el futuro famoso historiador de la Roma Antigua. Rostóvtsev y algunos otros profesores rusos, incluyendo el eminente historiador de arte Nikodim Kondakov, llegaron para estar algunos días en Madrid durante su viaje por Europa, pero no tenían ni idea de qué cosas hay que ver en la ciudad (ПИСКОРСКИЙ 1992: 188).

A diferencia de Botkin y de muchos otros viajeros por España, Piskorski elegía su itinerario guiándose exclusivamente por razones científicas. Visitó, entre otras ciudades, Valladolid con Simancas y Murcia, pero nunca fue a Andalucía. En cada lugar visitado por él, encontraba temas de su interés y trababa amistades.

Sus descripciones no carecen de algunos estereotipos muy habituales en los relatos sobre España, pero fue bien educado, tuvo gran amplitud de conocimientos y la inteligencia penetrante del historiador por profesión. Gracias a todo esto, fue capaz de crear en sus memorias una imagen a la vez expresiva y muy precisa del país estudiado.

\section{Referencias bibliográficas}

БОТКИН, В.П. (1976): Письма об Испании, Наука, Ленинград.

ГРАНОВСКИЙ, Т.Н. (1866): Сочинения, К. Солдатенков, Москва, ч. II, с. 166-189.

КОВАЛЕВСКИЙ, М.М. (1891): “Народ в драме Лопе де Веги «Овечий источник»”, en

В память С.А.Юрьева, И.Н. Кушнерев, Москва, с. 97-130

КОВАЛЕВСКИЙ, М.М. (1898-1903): Экономический рост Европы до возникновения капиталистического хозяйства, Москва, т. 1-3.

ЛУЧИЦКАЯ, С.И. (2011): "Начало испанистики в России и Украине", еn Родинний архів як сторінка вітчизняної історії, ЧНГУ, Чернігів, с. 45-53.

ЛУЧИЦКИЙ, И.В. $(1882,1883)$ : “Бегетрии: Очерк из истории испанских учреждений”, en Университетские известия, Киев, 1882, № 10; 1883, № 1 .

ЛучИЦКИЙ, И.В. (1883): “Поземельная община в Пиренеях", en Отечественные записки, № 9, с. 57-78; № 10, с. 467-506; № 12, с. 415-442.

МИЛЬСКАЯ, Л.Т., ПИЧУГИНА, И.С. (1975): "Русский историк-испанист - В.К. Пискорский (1867-1910 гг.)”, еn Проблемы испанской истории, Москва, с. 230-249.

МИЛЬСКАЯ, Л.Т., ПИЧУГИНА, И.С. (2000): “Владимир Константинович Пискорский”, en Портреты историков, т. 2, Москва - Иерусалим, с. 125-133.

НОВИКОВА-ПИСКОРСКАЯ, Е.А. (2010): “Из истории российско-испанских научных связей”, еn Испанский альманах, вып. 2. История и современность, Москва, с. 307-311.

НОВІКОВА, О.О. (2011): “Родинний архів як сторінка вітчизняної історії”, en Родинний архів як сторінка вітчизняної історії, ЧНГУ, Чернігів.

PISKORSKI, W. (1977): Las Cortes de Castilla en el periodo de tránsito de la Edad Media a la Moderna 1188-1520, El Albir, Barcelona. 
ПИСКОРСКИЙ, В.К. (1891): Франческо Ферруччи и его время: Очерк последней борьбы Флоренции за политическую свободу (1527-1530), Университетские известия, Киев.

ПИСКОРСКИЙ, В.К. (1992): “«Заграничные воспоминания» В.К. Пискорского (Из писем к жене, 1896-1897) / Публикация И.С. Пичугиной, Е.А. НовиковойПискорской”, еn Проблемы испанской истории, 1992, Москва, с. 178-191.

ПИСКОРСКИЙ, В.К. (1897): Кастильские кортесы в переходную эпоху от средних веков к новому времени (1188-1520), Киев.

ПИСКОРСКИЙ, В.К. (1898): “Отчет о заграничной командировке приват-доцента университета св. Владимира В. Пискорского за 1896 и 1897 гг.", еn Журнал Министерства народного просвещения, часть СССХХ, № 12, отд. 4, с. 19-47.

ПИСКОРСКИЙ, В.К. (1901): Крепостное право в Каталонии в средние века, Киев.

ПИСКОРСКИЙ, В.К. (1902): История Испании и Португалии, Санкт-Петербург (2-е изд., дополненное, Санкт-Петербург, 1909).

ПІСКОРСЬКИЙ, В.К. (1997): Вибрані твори та епістолярна спадщина, Фонд "Відродження", Київ.

ПИЧУГИНА, И.С. (2011): “К вопросу о наследии В.К. Пискорского”, еn Родинний архів як сторінка вітчизняної історії, ЧНГУ, Чернігів. 